\title{
MANUFACTURE AND PERFORMANCE EVALUATION OF A HORIZONTAL SINGLE-PASS ANIMAL FEED PELLETS COOLER
}

\author{
Morad, M. M.* and Hend A. M. El-Maghawry **
}

\section{ABSTRACT}

The present research was carried out to manufacture and evaluate the performance of a horizontal single-pass animal feed pellets cooler to improve product quality. The cooler performance was studied as a function of change in pellets feed rate, conveyor chain speed and airflow rate. Performance evaluation of the horizontal cooler was carried out in terms of final pellets moisture content, cooling efficiency, pellets durability, energy requirements and cooling cost.

The experimental results revealed that final pellets moisture content, cooling efficiency, pellets durability, energy requirements and cooling cost are in the optimum region under the following conditions:

- Pellets feed rate of $2.2 \mathrm{Mg} / \mathrm{h}$,

- Conveyor chain speed of $2 \mathrm{~cm} / \mathrm{s}$,

- Airflow rate of $12 \mathrm{~m}^{3} / \mathrm{s}$.

\section{INTRODUCTION}

ooling process of extruded pellets is one of the most important processes of animal feed pelleting. In production of feed pellets, it is necessary to control final moisture content and temperature to increase pellets quality and minimize costs. When pellets leave the pellet mill they are hot, soft and moist. In this condition, they cannot be transported or stored without being damaged. Therefore, a cooler is installed in close proximity to the press outlet in which the pellets can harden, moisture can evaporate and temperature can be reduced. During transport from pellet press to cooler, the hot pellets have to be treated gently, because they are still soft and break easily, resulting in a high percentage of fines.

* Prof. and Head of Agric. Eng. Dept., Fac. Of Agric., Zagazig Univ. **Lecturer of Agric. Eng., Fac. of Agric., Zagazig Univ. 
Pellet cooling is a dynamic process that involves simultaneous heat and mass transfer between the pellets and the cooling air. During cooling, two processes take place: heat transfer and mass transfer. The heat transfer from the pellets to the air is influenced by the temperature differences at the contact area, the size of the contact area and the heat conducting character of the pellets. Mass transfer means that moisture from the pellets is transferred to the process air. The cooling effect depends on moisture evaporation. Low number researches appear in the literature specifically on the cooling of feed pellets. Maier (1988) summarized the factors that affect the performance of a pellet cooler as: cooler type, air flow rate, temperature and humidity, pellet flow rate, temperature, moisture content, and size. Brooker et al. (1992) stated that there are various types of coolers that can be used to cool and dry pellets once they leave the mill. Some of the classic designs include: vertical style cooler, horizontal or belt style cooler, mixed rotary style cooler, and counter flow cooler. All of these designs use air as a convection and advection medium, but each design uses different means of exposing the pellets to the air. The four main methods for exposing pellets to drying air are: cross, concurrent, counter and mixed flow. Harper (1998) stated that the cooling and drying process is a crucial step in the production of feed pellet products. Using a dryer that requires a minimal amount of energy input is desirable to keep the production costs of pellets as low as possible. Additionally, when pellets are properly cooled and dried, they are less likely to produce dust, commonly called fines, or spoil from microbial and fungal growth. Fines are undesirable since they require more effort for the animal to consume and are more likely to be wasted. Fines also pose both safety and management issues in handling of the pellets. Fines and spoilage are both problems that can be minimized through proper cooling and drying of pellets. Heldman and Lund (2007) found that the amount of energy in the air and pellets as well as the amount of moisture in both the pellets and the air directly affect the cooling and drying process. Also they found that the methods of heat and mass transfer being employed: conduction, convection, absorption, adsorption, etc. significantly affects the cooling and drying process. Thus the type of cooler being used, the 
methods of heat and mass transfer and the cooler design employs will impact the cooling and drying process of feed pellets. Andersson and Johansson (2008) stated that in production of feed pellets it is necessary to have control of final moisture content and temperature to increase quality and minimize costs. They studied the steady state countercurrent flow feed pellet cooler and focused at model development (from theoretical physics), analyze of bed, and properties of air that gives good result. Two models are presented, the first one describes properties of air and pellets inside the cooler using differential equations. The second model only considers properties of inlet and outlet flows, independently of the interaction between air and pellets inside the cooler. The results showed that it is difficult to develop a model, based on theoretical physics for a countercurrent cooler. This is because it is difficult to determine drying rate. Further the results showed that air should be predried, i.e. to a relative humidity that is in equilibrium with desired moisture content of the outlet pellets. Steven (2008) studied the optimal sizing of a counter flow cooler for feed pellets. He used models developed to describe the cooling and drying of grains, which have been modified to describe feed pellets. Using these models, the author has developed and tested a system that can be used to estimate the temperature and moisture profiles for feed pellets in a counter flow cooler with any given cooler diameter, pellet size, airflow, product capacity, input temperature, input moisture content, and ambient conditions. His suggested model provided an indication of how variations in product size, product flow, airflow, cooler size, ambient conditions, and properties of the product upon entry will affect the performance of a counter flow cooler. Kaddour and Alavi (2010) manufactured and evaluated an aquatic feed pellet cooler of simple design by studying the effect of different operating parameters on final quality of floating and sinking aquatic feed. The studied cooler parameters included air suction velocity, cooler horizontal angle and turning speed. Their results showed that the optimum cooler parameters for good quality floating and sinking aquatic pellets were: air suction speed of 3.76-4.35 m/s, cooler turning speed of $10-15 \mathrm{rpm}$ and cooler angle of $10^{\circ}$ with $26.7-28.5{ }^{\circ} \mathrm{C}$ output temperature, $72.8-74.5 \%$ cooling 
efficiency, 8.3-9.1\% output moisture content, 0.1-0.8\% pellet losses and $0.8-1.7 \%$ breakage percentage.

Pellet cooling system performance is affected by many variables. The first are variables found in the air being used and include the air temperature and the amount of air passing through the cooler. Pellet variables include pellet temperature, moisture content, pellet size and density, and pellet quantity and quality. Cooler variables include product uniformity and system design.

\section{So, the objectives of the present study are to:}

- Manufacture of a horizontal single-pass animal feed pellets cooler from low cost local material to improve product quality.

- Optimize some operating parameters affecting the performance of the manufactured cooler (pellets feed rate, airflow rate and conveyor chain speed).

- Determine the energy required for operating the used cooler.

- Evaluate the used cooler from the economic point of view.

\section{MATERIALS AND METHODS}

The main experiments were carried out through the year of 2015 in a local factory in Alexandria Governorate to study the effect of some operating parameters on the performance of the horizontal single-pass animal feed pellets cooler.

\section{Materials}

\subsection{Experimental feed pellets}

Animal feed pellets were used to be cooled in the manufactured cooler. The animal feed formulation consisted of the following ingredients: Soybean meal (19\%), Yellow corn (7.5\%), Barley (10\%), coarse wheat bran (20\%), fennel and caraway straw (17.35\%), fenugreek seed meal (3\%), alfalfa dehydrated meal $(13 \%)$, rice bran $(7 \%)$, salt $(0.5 \%)$, lime stone $(1.6 \%)$, non-food additives $(1.05 \%)$.

Prior to extrusion, the above mix was blended in a batch horizontal mixer. Then, cylindrical shaped animal feed pellets were produced on a single-screw extruder. The average diameter and length of the produced animal feed pellets were 6.0 and $9.0 \mathrm{~mm}$. 


\subsection{The manufactured horizontal single-pass pellets cooler}

A local pellets cooler was manufactured from low cost, local material to overcome the problems of high power and high cost requirements under the use of the imported coolers. The local cooler was manufactured at a small workshop in Alexandria Governorate.

The manufactured cooler must meet several requirements. It must be:

- Designed to effectively cool a range of products by removing enough heat and moisture for further handling or storage of the pellets.

- Able to do the above tasks while avoiding over drying of the pellets. Removal of more moisture than required results in removing extra mass (weight) that results in losing selling weight.

- Reliable and provide gentle handling of the pellets that minimizes creation of fines in the process.

- Under control of airflow rate to pass uniformly through the product. The manufactured cooler consists of the following main parts (Fig. 1):

\section{- Feed pellets transfer gates:}

A transfer gate at the entrance of the cooling chamber is used to allow animal feed pellets to flow through it to the cooler. Another gate at the end of the cooling chamber is used to collect the output-cooled pellets.

\section{- The cooling chamber:}

The cooling chamber is of a rectangular shape. Its dimensions are 435 $\mathrm{cm}$ length, $155 \mathrm{~cm}$ width and $130 \mathrm{~cm}$ height and is made of milled steel with a thickness of $8 \mathrm{~mm}$. Cooling chamber corners are fillet welded.

\section{- The conveyor chain:}

The conveyor chain, with dimensions of $395 \mathrm{~cm}$ in length (from center of drive to center of driven pulleys) and $130 \mathrm{~cm}$ in width, was constructed on drive and driven pulleys. The drive and driven pulleys have the same diameter of $20 \mathrm{~cm}$. The conveyor chain consists of 86 strips. Every strip has a rectangular shape $(130 \mathrm{~cm}$ length, $11 \mathrm{~cm}$ width and $2 \mathrm{~mm}$ thickness). Every strip is perforated with parabolic holes to allow fine and damaged pellets to be separated and passing through the holes and collected from a gate below the cooling chamber while the cooled pellets are conveyed to the out-let gate. 


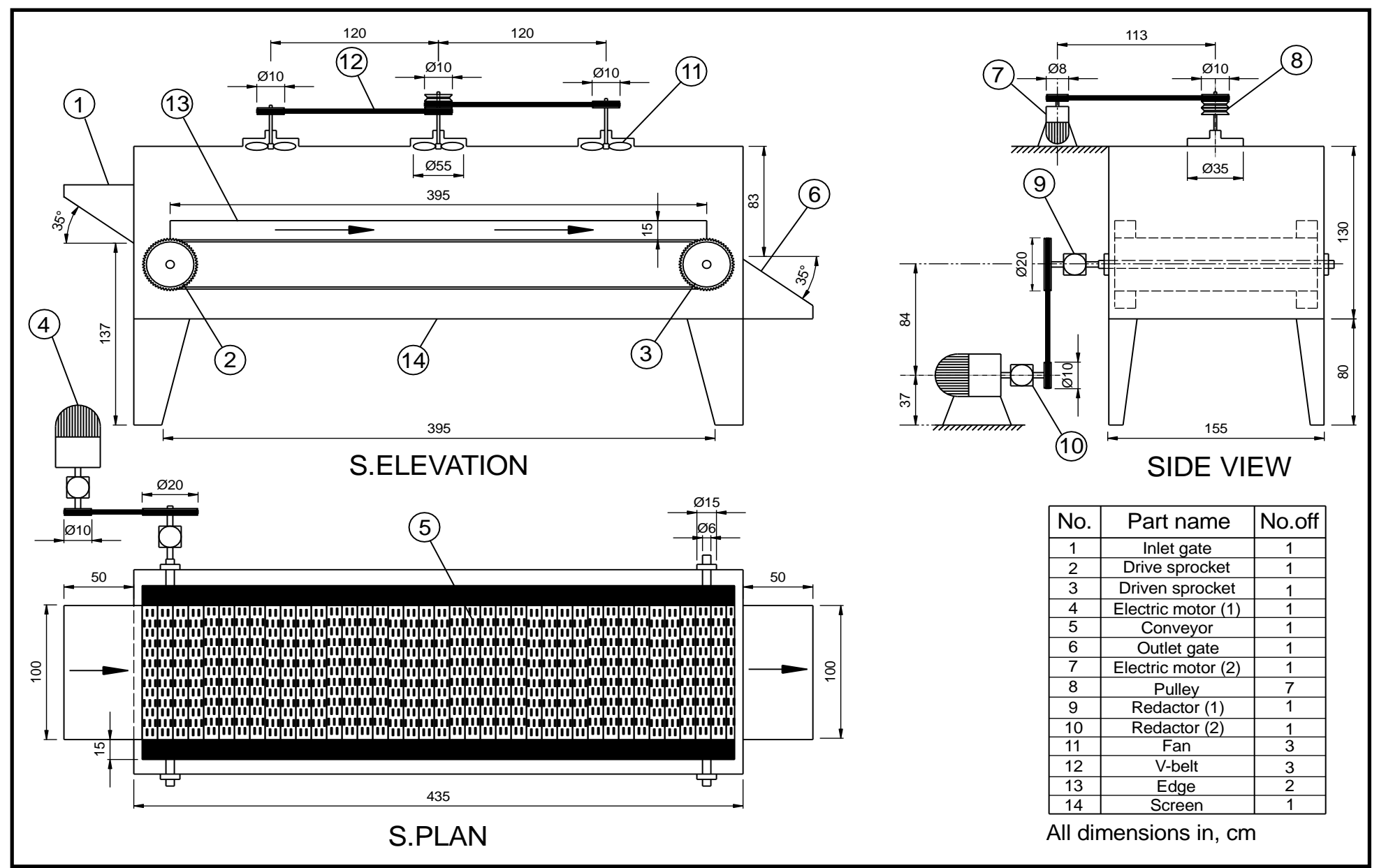

Fig. (1): The schematic drawing of the manufactured single-pass feed pellets cooler. 


\section{- The cooling system:}

The cooling system is a combination of three cooling fans supported at the top of the cooling chamber to push air through the passing feed pellets, which are moved above the carrying chain. Each fan is $55 \mathrm{~cm}$ in diameter, having six blades. Cooling fans take their motion from electric motor by means of pulleys and belts.

\section{- Cooler drive and driven shafts:}

The conveyor chain drive shaft is a rotating member of circular cross section, which transmits power. The shaft is made of iron steel and supported by two rolling bearings. It is operated by means of pulley and belt powered from the electric motor. The shaft length and diameter are $155 \mathrm{~cm}$ and $60 \mathrm{~mm}$, respectively. The driven shaft is similar to the drive shaft in cross section and dimensions except that it takes his motion from the drive shaft through the conveyor chain.

\section{- Bearings}

Each of the two drive and driven shafts are supported by two rolling bearings. The manufacturer's catalogue is used to select the suitable type of the rolling bearings. According to the manufacturer's catalogue, the anti friction ball bearing is selected.

\section{- The cooler frame}

The cooler frame, which carries all the cooler parts, is made of heavy structural steel (I) section of $12 \mathrm{~mm}$ thickness to prevent any vibration during the cooling operation. Cooler supports are welded to cooler body, providing reasonable working clearance underneath.

\section{- The power sources}

The manufactured cooler was powered by two electric motors: The first one is $2.6 \mathrm{~kW}(3.5 \mathrm{hp})$ at a rotated speed of $900 \mathrm{rpm}$ for operating the cooling fans. The other one is $0.74 \mathrm{~kW}(1.0 \mathrm{hp})$ at a rotated speed of 900 rpm for operating the conveyor chain. 


\section{- The transmission system}

The fan shaft is operated by means of pulley (100 mm diameter) and belt powered from the electric motor pulley ( $80 \mathrm{~mm}$ diameter). The power is transmitted from the motor pulley to the fan shaft by gearbox with different speed ratios.

The conveyor chain shaft is operated by means of chain pulley ( $200 \mathrm{~mm}$ diameter) and belt powered from the electric motor pulley ( $100 \mathrm{~mm}$ diameter). The power is transmitted from the motor pulley to the conveyor chain shaft by gearbox with different speed ratios.

\section{2- Methods}

Experiments were carried out to evaluate the performance of the manufactured horizontal single-pass animal feed pellets cooler to optimize values of the main operating parameters.

\subsection{Experimental conditions}

The performance of the manufactured horizontal single-pass animal feed pellets cooler was experimentally measured under the following parameters:

- Four values of pellets feed rate of (1.8, 2.0, 2.2 and $2.4 \mathrm{Mg} / \mathrm{h})$.

- Four values of conveyor chain speed of $(1,2,3$ and $4 \mathrm{~cm} / \mathrm{s})$.

- Three values of airflow rate of $\left(4,8\right.$ and $\left.12 \mathrm{~m}^{3} / \mathrm{s}\right)$

\subsection{Measurements and determinations}

Performance evaluation of the manufactured cooler was based on the following indicators:

\section{- Pellets moisture content:}

Pellet moisture contents, expressed on a wet basis, were measured using oven drying $\left(135{ }^{0} \mathrm{C}\right.$ for $\left.2 \mathrm{~h}\right)$ according to the American Association of Cereal Chemists Approved Method 44-19 (AACC 2000).

\section{- Cooling efficiency:}

Cooling efficiency was calculated using the following relation:

Cooling efficiency $(\%)=\frac{T_{1}-T_{2}}{T_{1}} \times 100$

Where: $\mathrm{T}_{1}$ - Pellets input temperature, ${ }^{0} \mathrm{C}$, $\mathrm{T}_{2}$ - Pellets output temperature, ${ }^{0} \mathrm{C}$. 


\section{- Pellets durability:}

One kilogram of feed pellets is turned in a sieve shaker for ten minutes. After the shaking treatment, the cracked and the damaged pellets are subtracted from the treated sample. So, pellets durability can be calculated as follows:

Pellets durability $=\frac{W_{a}}{W_{b}} \times 100$

Where: $\mathrm{W}_{\mathrm{a}}$ - Pellets mass after shaker treatment, $\mathrm{g}$,

$\mathrm{W}_{\mathrm{b}}$ - Pellets mass before shaker treatment, $\mathrm{g}$.

\section{- Specific energy requirements}

The energy requirements for the cooling operation can be calculated as follows:

Specific energy requirements $(\mathrm{kW} . \mathrm{h} / \mathrm{Mg})=\frac{\text { Required power }(\mathrm{kW})}{\text { Pellets feed rate }(\mathrm{Mg} / \mathrm{h})}$

The required power is a summation of two powers as follows:

Required power $=\mathrm{FP}+\mathrm{CP}$

Where:

FP - power required for operating cooling fans, $\mathrm{kW}$,

$\mathrm{CP}$ - power required for operating conveyor chain, $\mathrm{kW}$.

The following formula was used to estimate the required cooling power (Kurt, 1979):

$$
\mathrm{P}=\sqrt{3} \times \cos \varphi \times \mathrm{I} \times \mathrm{V} / 1000
$$

Where:

P - Required power, $\mathrm{kW}$,

I - Current intensity, Ampere,

$\mathrm{V}$ - Voltage, $(380 \mathrm{~V})$,

$\cos \varphi-0.7$

\section{- Cooling cost}

The cooler hourly cost is estimated according to the conventional method of estimating both fixed and variable costs. While cooling cost was calculated using the following formula:

Cooling $\operatorname{cost}(\mathrm{L} . \mathrm{E} . / \mathrm{Mg})=\frac{\text { Cooler hourly cost }(\mathrm{L} . \mathrm{E} . / \mathrm{h})}{\text { Pellets feed rate }(\mathrm{Mg} / \mathrm{h})}$ 


\section{RESULTS AND DISCUSSIONS}

The discussion will cover the obtained results under the following heads:

\section{Effect of some operating parameters on the final pellets moisture content}

A primary outcome of the cooling process is removal of moisture from the pellets. The final pellet moisture content is therefore a very important parameter, from the point of view of stability during handling and long-term storage of pellets. The moisture of the pellets entering the cooler after extruding process ranged between 15 to $17 \%$.

Representative values of final pellets moisture content versus pellets feed rate are given through various airflow rates in Fig. 2. The obtained results show that the increase of pellets feed rate from 1.8 to $2.4 \mathrm{Mg} / \mathrm{h}$, was accompanied with an increase in the pellets moisture content from 7.1 to 11.8 , from 6.1 to 9.8 and from 5.2 to $7.5 \%$ at airflow rates of 4,8 , and $12 \mathrm{~m}^{3} / \mathrm{s}$, respectively. That is may be attributed to the excessive load of pellets on the conveying chain which decreasing the chance of projecting pellets to the air flow, resulting in exiting pellets with high moisture.
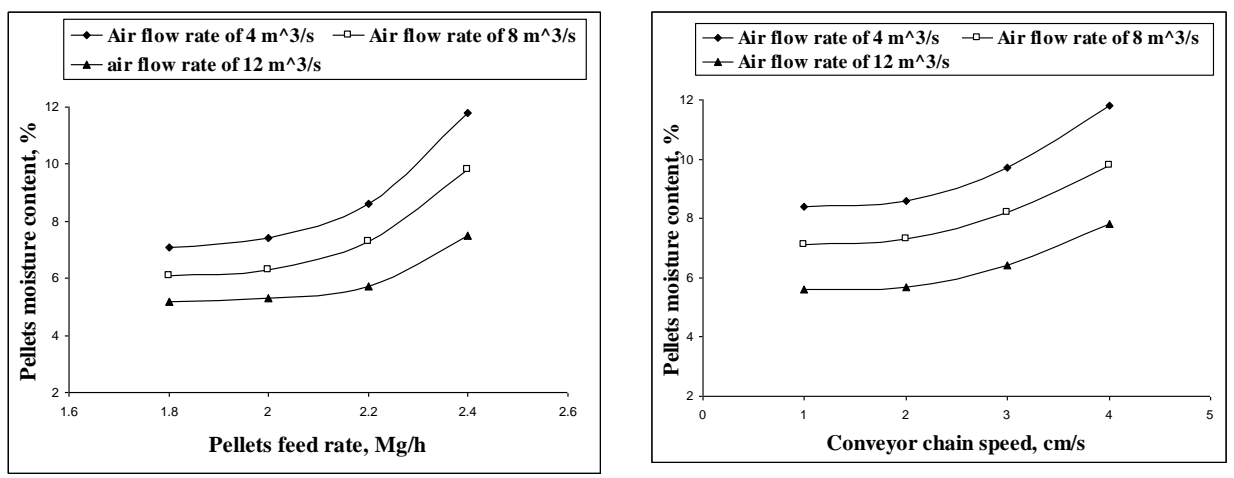

Fig. (2): Effect of pellets feed rate, conveyor chain speed and air flow rate on pellets moisture content

The effects of conveyor chain speed on the final pellets moisture content at different airflow rates are shown in Fig. 2. Results show that increasing conveyor chain speed from 1 to $4 \mathrm{~cm} / \mathrm{s}$, the pellets moisture content increased from 8.4 to 11.8 , from 7.1 to 9.8 and from 5.6 to $7.8 \%$ at airflow rates of 4,8 , and $12 \mathrm{~m}^{3} / \mathrm{s}$, respectively. The reason of that can be due to the fast motion of pellets with the high speed of the conveyor 
chain that decreasing the chance of projecting pellets to the airflow, resulting in exiting pellets with high moisture.

As to the effect of airflow rate on the final pellets moisture content, results in Fig. 2 show that increasing airflow rate from 4 to $12 \mathrm{~m}^{3} / \mathrm{s}$, decreased pellets moisture content from 8.6 to $5.7 \%$ under conditions of $2.2 \mathrm{Mg} / \mathrm{h}$ pellets feed rate and $2 \mathrm{~cm} / \mathrm{s}$ conveyor chain speed. Increasing final pellets moisture content by increasing airflow rate is attributed to exposing pellets to large amount of air, resulting in removing much moisture from the pellets. Moreover, higher values of airflow rate would lead to increase in the surface mass transfer coefficient, and thus increase in the cooling rate as well.

\section{Effect of some operating parameters on the cooling efficiency}

In production of feed pellets, it is necessary to have control of final temperature to increase pellets quality. So, cooling efficiency is a very important parameter for evaluation of any cooling system as it takes into account both input and output temperatures of the pellets.

The obtained results in Fig. 3 show that increasing pellets feed rate from 1.8 to $2.4 \mathrm{Mg} / \mathrm{h}$, the cooling efficiency decreased from 71 to 57 , from 78 to 68 and from 85 to $78 \%$ at airflow rates of 4,8 , and $12 \mathrm{~m}^{3} / \mathrm{s}$, respectively. Decreasing cooling efficiency by increasing pellets feed rate is attributed to the excessive load of pellets on the conveyor chain which decreasing the chance of projecting pellets to the air flow, resulting in exiting pellets with high temperature.
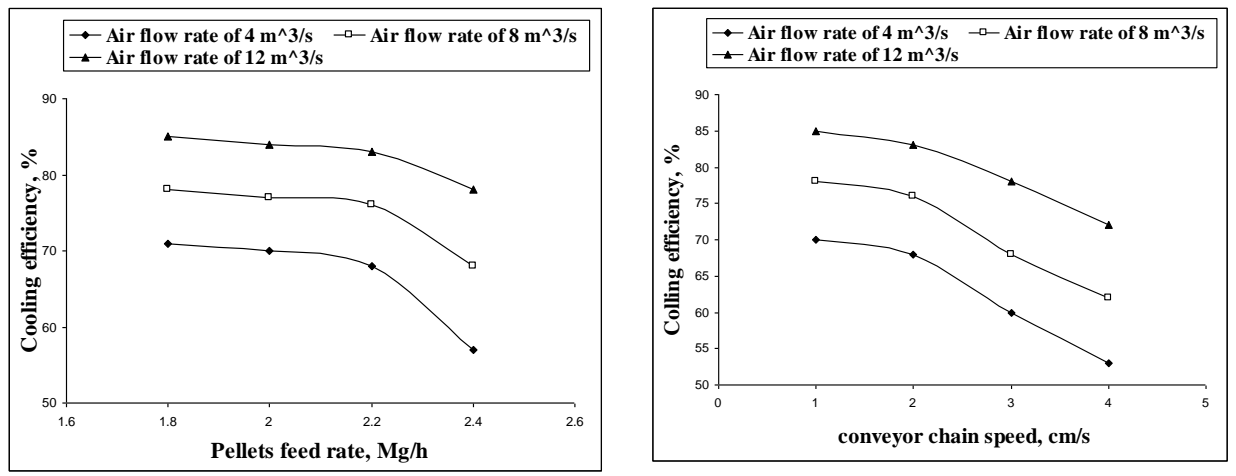

Fig. (3): Effect of pellets feed rate and conveyor chain speed on cooling efficiency under different air flow rates 
Relating to the effect of conveyor chain speed on cooling efficiency Data in Fig. 3 show that increasing conveyor chain speed from 1 to 4 $\mathrm{cm} / \mathrm{s}$, the cooling efficiency decreased from 70 to 53 , from 78 to 62 and from 85 to $72 \%$ at airflow rates of 4,8 , and $12 \mathrm{~m}^{3} / \mathrm{s}$, respectively. Decreasing cooling efficiency by increasing conveyor chain speed is attributed to the fast motion of pellets with the high speed of the conveyor chain that decreasing the chance of projecting pellets to the airflow, resulting in exiting pellets with high temperature.

As to the effect of airflow rate on cooling efficiency, results in Fig. 3 show that increasing airflow rate from 4 to $12 \mathrm{~m}^{3} / \mathrm{s}$, increased cooling efficiency from 68 to 83 under conditions of $2.2 \mathrm{Mg} / \mathrm{h}$ pellets feed rate and $2 \mathrm{~cm} / \mathrm{s}$ conveying chain speed. Increasing cooling efficiency by increasing airflow rate is attributed to exposing pellets to large amount of air, resulting in reducing final temperature of the pellets.

\section{Effect of some operating parameters on the pellets durability}

Pellets durability is considered one of the most important indicators of pellets quality. The cooling process leads to increase pellets durability.

Representative values of pellets durability versus pellets feed rate are given through various airflow rates in Fig. 4. The obtained results show that increasing pellets feed rate from 1.8 to $2.4 \mathrm{Mg} / \mathrm{h}$, the pellets durability decreased from 83 to 70 , from 90 to 80 and from 96 to $88 \%$ at airflow rates of 4,8 , and $12 \mathrm{~m}^{3} / \mathrm{s}$, respectively. Decreasing pellets durability by increasing pellets feed rate is attributed to the excessive load of pellets on the conveying chain which decreasing the chance of projecting pellets to the air flow, resulting in exiting pellets with high moistures and high temperature that tends to decrease pellets stability.

Relating to the effect of conveyor chain speed on the pellets durability, data in Fig. 4 show that increasing conveyor chain speed from 1 to 4 $\mathrm{cm} / \mathrm{s}$, the pellets durability decreased from 82 to 68 , from 89 to 80 and from 95 to $88 \%$ at airflow rates of 4,8 , and $12 \mathrm{~m}^{3} / \mathrm{s}$, respectively. Decreasing pellets durability by increasing conveyor chain speed is attributed to the fast motion of pellets with the high speed of the conveying chain that decreasing the chance of projecting pellets to the airflow, resulting in exiting pellets with high temperature that tends to decrease pellets resistance for durability test. 

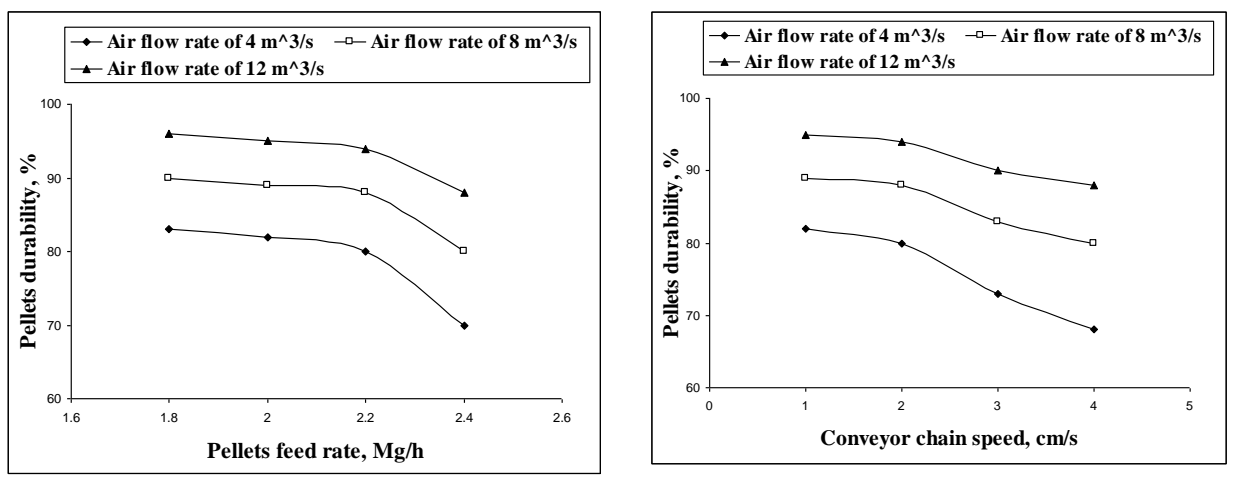

Fig. (4): Effect of pellets feed rate, conveyor chain speed and air flow rate on pellets durability

As to the effect of airflow rate on pellets durability, results in Fig. 4 show that increasing airflow rate from 4 to $12 \mathrm{~m}^{3} / \mathrm{s}$, increased pellets durability from 80 to 94 under conditions of $2.2 \mathrm{Mg} / \mathrm{h}$ pellets feed rate and $2 \mathrm{~cm} / \mathrm{s}$ conveying chain speed. Increasing pellets durability by increasing airflow rate is attributed to exposing pellets to large amount of air, resulting in reducing final temperature of the pellets, tending to increase pellets stability.

\section{Effect of some operating parameters on energy requirements}

Power and energy requirements are too related to pellets feed rate under all airflow rates as shown in Fig. 5. Experimental data show that increasing pellets feed rate increased the required power. While the same data show that the energy requirements vary inversely with pellets feed rate to a certain extent. It is clear that energy requirements were decreased by increasing pellets feed rate up to $2.2 \mathrm{Mg} / \mathrm{h}$. Any further increase in pellets feed rate up to $2.4 \mathrm{Mg} / \mathrm{h}$, energy requirements will increase. Obtained results show that increasing pellets feed rate from 1.8 to $2.2 \mathrm{Mg} / \mathrm{h}$ measured at different airflow rates of 4,8 and $12 \mathrm{~m}^{3} / \mathrm{s}$, decreased energy requirements from 0.62 to 0.52 , from 0.94 to 0.80 and from 1.2 to $1.0 \mathrm{~kW} . \mathrm{h} / \mathrm{Mg}$, respectively at constant conveyor chain speed of $2 \mathrm{~cm} / \mathrm{s}$. The further increase in pellets feed rate more than 2.2 up to $2.4 \mathrm{Mg} / \mathrm{h}$, measured at the same previous airflow rates, increased energy requirements from 0.52 to 0.57 , from 0.80 to 0.83 and from 1.0 to 1.05 $\mathrm{kW} . \mathrm{h} / \mathrm{Mg}$, respectively under the same mentioned conveyor chain speed. 
The required power increased by increasing pellets feed rate because of the increase of pellets flow on the conveyor chain at the same time unit, which represents extensive load on the conveyor chain shaft resulting in more power. The higher values of pellets feed rate more than the optimum value $(2.2 \mathrm{Mg} / \mathrm{h})$ tends to increase energy because of the high increase in the required power comparing with the increase in pellets feed rate.

Power and energy requirements are also related to conveyor chain speed under all airflow rates as shown in Fig. 5. Experimental data show that increasing conveyor chain speed increased both required power and energy requirements. Obtained results show that increasing conveyor chain speed from 1 to $4 \mathrm{~cm} / \mathrm{s}$, measured at different airflow rates of 4,8 and $12 \mathrm{~m}^{3} / \mathrm{s}$, increased energy requirements from 0.5 to 0.66 , from 0.78 to 0.93 and from 0.98 to $1.22 \mathrm{~kW} . \mathrm{h} / \mathrm{Mg}$, respectively at constant pellets feed rate of $2.2 \mathrm{Mg} / \mathrm{h}$.
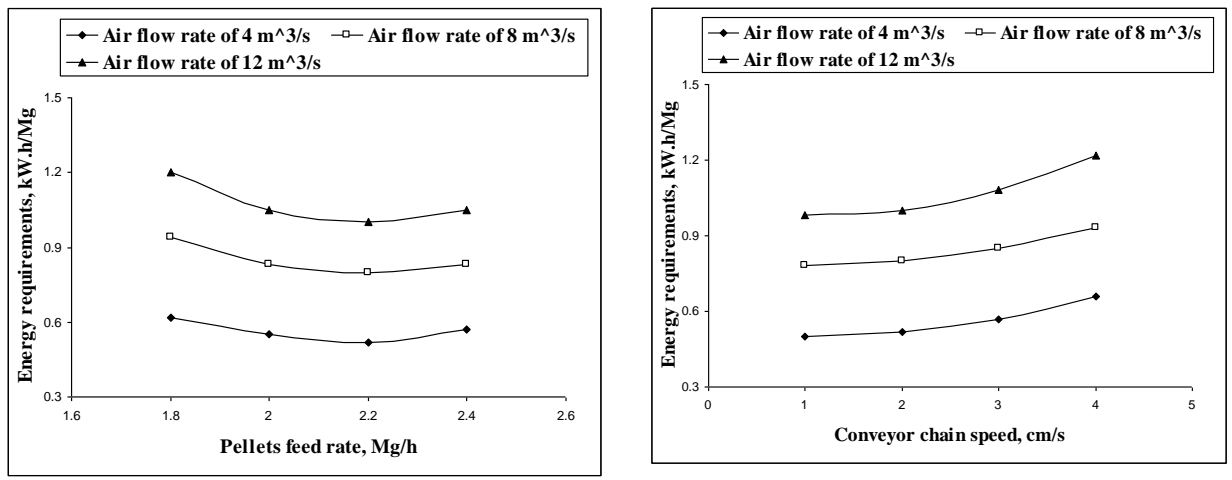

Fig. (5): Effect of pellets feed rate, conveyor chain speed and air flow rate on energy requirements

The required power as well as energy requirements increased by increasing conveyor chain speed because of the increase in friction force between the conveyor chain shaft and its bearings, added to that the conveyor chain surface, in this case, is subjected to high pressure forces associated with the fast sliding of pellets resulting in more power and energy.

As to the effect of airflow rate on energy requirements, results in Fig. 5 show that increasing airflow rate from 4 to $12 \mathrm{~m}^{3} / \mathrm{s}$, increased energy 
requirements from 0.52 to $1.0 \mathrm{~kW} . \mathrm{h} / \mathrm{Mg}$ under conditions of $2.2 \mathrm{Mg} / \mathrm{h}$ pellets feed rate and $2 \mathrm{~cm} / \mathrm{s}$ conveyor chain speed. Increasing energy requirements by increasing airflow rate is attributed to the high power required for operating cooling fans at high speeds.

\section{Effect of some operating parameters on the cooling cost}

Cooling cost is strongly related to pellets feed rate under all airflow rates as shown in Fig. 6. The obtained data show that increasing pellets feed rate decreased the cooling cost up to $2.2 \mathrm{Mg} / \mathrm{h}$. Any further increase in pellets feed rate up to $2.4 \mathrm{Mg} / \mathrm{h}$, cooling cost will increase. Obtained results show that increasing pellets feed rate from 1.8 to $2.2 \mathrm{Mg} / \mathrm{h}$ measured at different airflow rates of 4,8 and $12 \mathrm{~m}^{3} / \mathrm{s}$, decreased cooling cost from 32 to 16 , from 37 to 23 and from 43 to 30 L.E./Mg, respectively at constant conveyor chain speed of $2 \mathrm{~cm} / \mathrm{s}$. The further increase in pellets feed rate more than 2.2 up to $2.4 \mathrm{Mg} / \mathrm{h}$, measured at the same previous airflow rates, increased cooling cost from 16 to 17 , from 23 to 25 and from 30 to $32 \mathrm{~L}$.E. $/ \mathrm{Mg}$, respectively under the same mentioned conveyor chain speed. The cooling cost decreased by increasing pellets feed rate less than the optimum value $(2.2 \mathrm{Mg} / \mathrm{h})$ because of the high increase in pellets feed rate comparing with the increase in the price of the required power. The higher values of pellets feed rate more than the optimum value $(2.2 \mathrm{Mg} / \mathrm{h})$ tends to increase cooling cost because of the high increase in the price of the required power comparing with the increase in pellets feed rate resulting in high cooling cost.
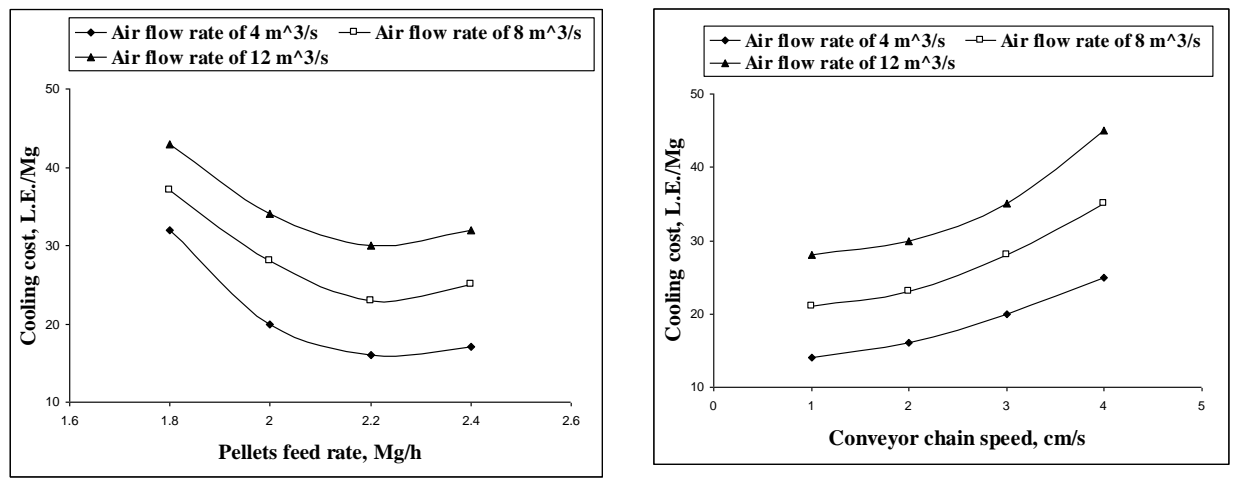

Fig. (6): Effect of pellets feed rate, conveyor chain speed and air flow rate on cooling cost 
Cooling cost is also related to conveyor chain speed under all airflow rates as shown in Fig. 6. Obtained results show that increasing conveyor chain speed from 1 to $4 \mathrm{~cm} / \mathrm{s}$, measured at different airflow rates of 4,8 and $12 \mathrm{~m}^{3} / \mathrm{s}$, increased cooling cost from 14 to 25 , from 21 to 35 and from 28 to 45 L.E./Mg, respectively at constant pellets feed rate of 2.2 $\mathrm{Mg} / \mathrm{h}$. The cooling cost increased by increasing conveyor chain speed because the conveyor chain surface is subjected to high-pressure forces associated with the fast sliding of pellets resulting in more required power, as a result cooling cost increased. As to the effect of airflow rate on cooling cost, results in Figs. 6 show that increasing airflow rate from 4 to $12 \mathrm{~m}^{3} / \mathrm{s}$, increased cooling cost from 16 to 30 L.E./Mg under conditions of $2.2 \mathrm{Mg} / \mathrm{h}$ pellets feed rate and $2 \mathrm{~cm} / \mathrm{s}$ conveyor chain speed. Increasing cooling cost by increasing airflow rate is attributed to the high power required for operating cooling fans at high speeds, resulting in high cooling cost.

\section{CONCLUSION}

In production of feed pellets, it is necessary to control final moisture content and temperature to increase pellets quality for long-term storage, minimize energy and costs. The experimental results revealed that final pellets moisture content, cooling efficiency, pellets durability, energy requirements and cooling cost are in the optimum region under some conditions. To achieve that, the proper operational conditions for pellet cooler are: $2.2 \mathrm{Mg} / \mathrm{h}$ pellets feed rate, $2 \mathrm{~cm} / \mathrm{s}$ conveyor chain speed and $12 \mathrm{~m}^{3} / \mathrm{s}$ airflow rate.

\section{REFERENCES}

AACC. (2000). Approved Methods of AACC, 10th Ed., American Association of Cereal Chemists, St. Paul, MN.

Andersson, D. and D. Johansson (2008). Mathematical model for countercurrent feed pellet cooler. M. Sc. Thesis. Chalmers of University Technology. Göteborg, Sweden.

Brooker, D.B., F.W. Bakker-Arkema, and C. W. Hall. (1992). Drying and Storage of Grains and Oilseeds. Van Nostrand Reinhold. New York, NY. 
Harper, Allen. (1998). The importance of pellet quality in hog feeding. Livestock Update.

Available at: http://www.ext.vt.edu/news/periodicals/livestock/aps98_09/aps-969.html.

Heldman, D.R. and D.B. Lund. (2007). Handbook of Food Engineering. Second Edition. CRC Press. Boca Raton, FL.

Kaddour, O. and S. Alavi (2010). Manufacture and evaluation of a single-pass rotary cooler for aquatic feed pellets. Journal of Food Process Engineering 33: 585-605.

Maier, D.E. (1988). The counterflow cooling of feed pellets. M.S. Thesis. Michigan State University. East Lansing, MI.

Steven L. F. (2008). Optimal sizing of a counterflow cooler for feed pellets. M.S. Thesis. Oklahoma State Univ. Stillwater, Oklahoma.

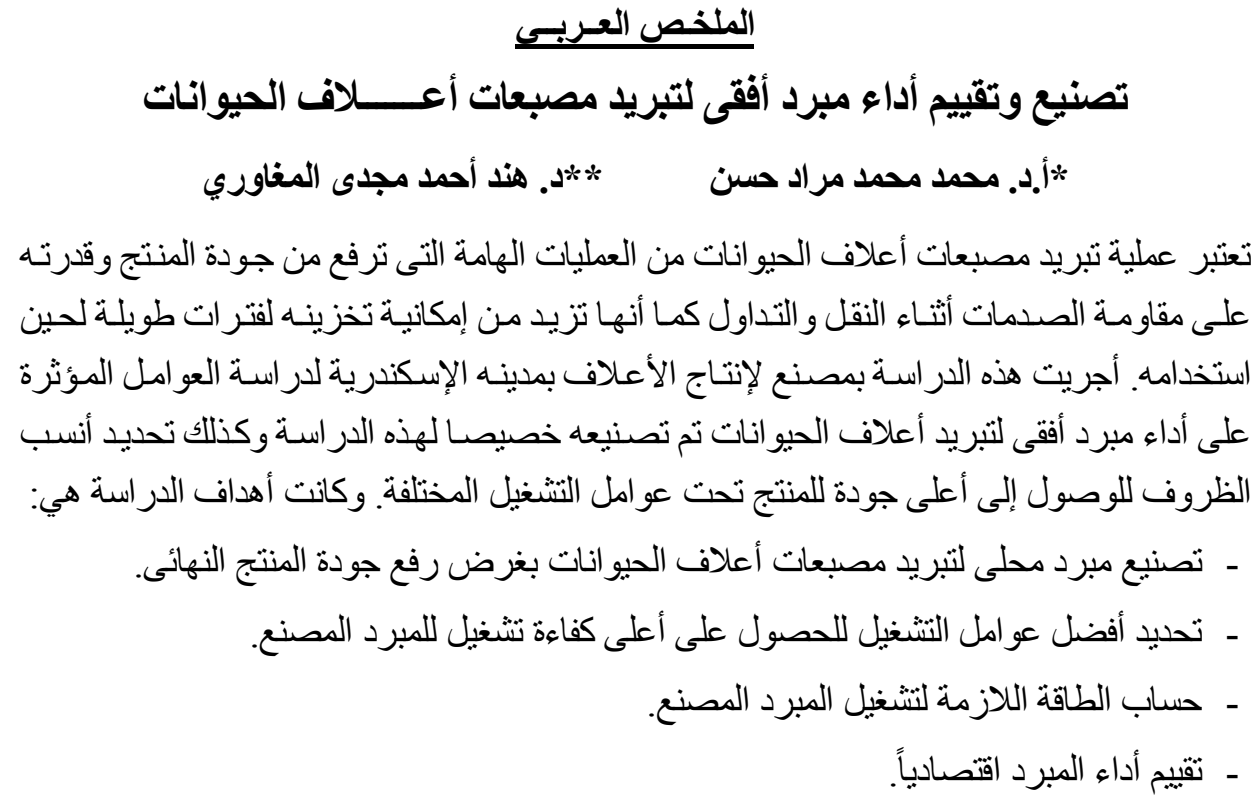

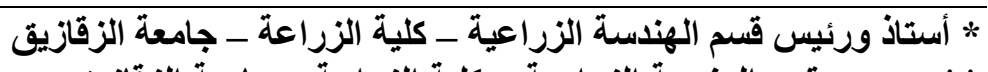

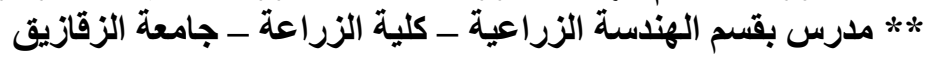




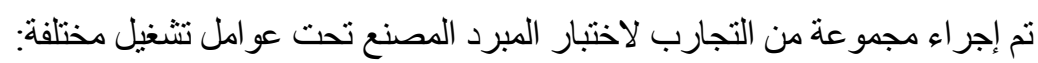

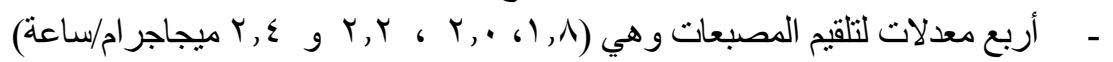

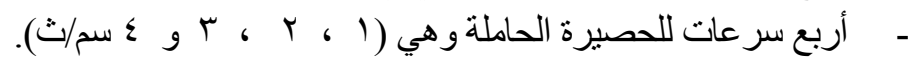

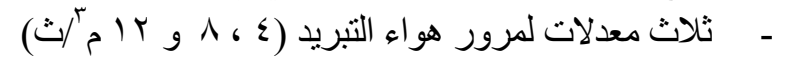
وقد تم تقييم المعاملات السابقة أخذاً في الاعتبار كلاً من:

- نسبة رطوبة مصبعات العلف بعد التبريد -

- مقاومة مصبعات العلف للنقل و الصدمات

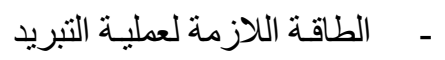
- م - التكاليف اللازمة لإجراء عملية التبريد.

وقد أظهرت النتائج التجريبية أن كفاءة تبريد المصبعات تكون أعلى ما يمكن فى حين تكون الطاقة

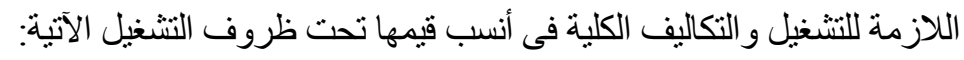

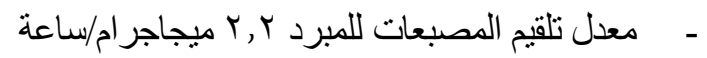

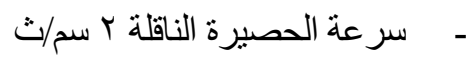

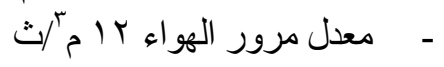

